\title{
A change from gonadotropin releasing hormone antagonist to gonadotropin releasing hormone agonist therapy does not affect the oncological outcomes in hormone sensitive prostate cancer
}

\author{
Jumpei Asakawa ${ }^{1}$, Taro Iguchi ${ }^{1}$, Satoshi Tamada ${ }^{1 *}$ (D), Sayaka Yasuda ${ }^{1}$, Noriko Ninomiya ${ }^{1}$, Minoru Kato',
}

Takeshi Yamasaki ${ }^{1}$, Tetusji Ohmachi ${ }^{2}$ and Tatsuya Nakatani ${ }^{1}$

\begin{abstract}
Background: The aim of our retrospective study was to evaluate the 5-year survival and time to castration resistant prostate cancer in patients with hormone sensitive prostate cancer treated with the gonadotropin releasing hormone antagonist, degarelix. Another aim was to evaluate the effects of changing the treatment from degarelix to a gonadotropin releasing hormone agonist after achieving stable disease control, on the clinical and oncological outcomes.

Results: Our analysis was based on the data of 108 patients with prostate cancer who were treated with degarelix. Of these, the treatment was changed from degarelix to a gonadotropin releasing hormone agonist in 57 patients (changed group), and the treatment with degarelix was continued in the other 51 (continued group). The overall 5 -year survival was statistically superior in the changed (96.6\%) group than that in the continued (74.1\%) group $(p=0.006)$. The 5 -year cancer-specific survival was also superior in the changed $(100 \%)$ group than that in the continued (84.6\%) group ( $p=0.027)$. The average time to castration resistant prostate cancer was comparable in both the changed (43.3 months) and continued (35.2 months) groups ( $p=0.117$ ). Lower serum levels of prostate specific antigen and alkaline phosphatase were maintained after changing the therapy from degarelix to a gonadotropin releasing hormone agonist.
\end{abstract}

Conclusions: Degarelix is effective in the treatment of prostate cancer. Degarelix therapy can also be safely changed to a gonadotropin releasing hormone agonist without any adverse clinical or oncological effects.

Keywords: Gonadotropin releasing hormone antagonists and inhibitors, Gonadotropin releasing hormone agonists, Prostate cancer, Degarelix, Castration-resistant

\footnotetext{
* Correspondence: s-tamada@med.osaka-cu.ac.jp

'Department of Urology, Osaka City University Graduate School of Medicine,

1-4-3 Asahi-machi, Abeno-ku, Osaka 545-8585, Japan

Full list of author information is available at the end of the article
}

(C) The Author(s). 2018 Open Access This article is distributed under the terms of the Creative Commons Attribution 4.0 International License (http://creativecommons.org/licenses/by/4.0/), which permits unrestricted use, distribution, and reproduction in any medium, provided you give appropriate credit to the original author(s) and the source, provide a link to the Creative Commons license, and indicate if changes were made. The Creative Commons Public Domain Dedication waiver (http://creativecommons.org/publicdomain/zero/1.0/) applies to the data made available in this article, unless otherwise stated. 


\section{Résumé}

Contexte: L'objectif de notre étude rétrospective était d'évaluer la survie à 5 ans et le délai de transition du cancer de la prostate hormono-sensible au cancer de la prostate résistant à la castration chez des patients porteurs d'un cancer de la prostate hormono-sensible qui étaient traités par un antagoniste de la gonadolibérine, le dégarélix. Un autre objectif était d'évaluer les effets sur les résultats cliniques et oncologiques du remplacement du dégarélix par un agoniste de la gonadolibérine après obtention d'un état stable et contrôlé.

Résultats: Notre analyse repose sur les données de 108 patients atteints d'un cancer de la prostate traités par dégarélix. Parmi ceux-ci, le traitement par dégarélix a été remplacé par un agoniste de la gonadolibérine chez 57 (groupe modifié), et le traitement par dégarélix a été poursuivi chez les autres patients (groupe inchangé). La survie globale à 5 ans était statistiquement plus élevée pour le groupe modifié (96.6\%) que pour le groupe inchangé (74,1\%; $p=0.006)$. Les chances de survie cancer-spécifiques à 5 ans était également plus élevées pour le groupe modifié $(100 \%)$ que pour le groupe inchangé $(84,6 \% ; p=0.027)$. Le délai moyen de transition du cancer de la prostate hormono-sensible au cancer de la prostate résistant à la castration était comparable dans le groupe modifié (43,3 mois) et dans le groupe inchangé (35,2 mois). Des taux sériques plus bas d'antigène spécifique de la prostate et de phosphatase alcaline ont été maintenus après le remplacement du dégarélix par un agoniste de la gonadolibérine.

Conclusions: Le dégarélix est. efficace dans le traitement du cancer de la prostate. Le traitement par dégarélix peut aussi être remplacé en toute sécurité par un agoniste de la gonadolibérine sans aucun effet clinique ou oncologique indésirable.

Mots-clés: Antagonistes et inhibiteurs de la gonadolibérine, Agoniste de la gonadolibérine, Cancer de la prostate, Dégarélix, Résistant à la castration

\section{Background}

Prostate cancer (PCa) is one of the most common cancers worldwide, with a survival rate that is relatively high in comparison with that of other cancers, partially due to the effectiveness of androgen deprivation therapy (ADT), even in patients with metastatic PCa. Ever since Huggins and Hodges [1] demonstrated that surgical castration resulted in significant clinical improvement in patients with advanced $\mathrm{PCa}$, ADT has become the main treatment for PCa. The most commonly used agents for $\mathrm{ADT}$ are gonadotropin releasing hormone $(\mathrm{GnRH})$ agonists. Although ADT can be effective in achieving testosterone levels comparable to those following castration $(<0.5 \mathrm{ng} / \mathrm{ml})$, an initial testosterone surge is commonly observed, which can lead to an exacerbation of clinical symptoms, including urinary retention and aggravation of bone metastases [2]. To overcome this phenomenon, degarelix was developed as a novel GnRH antagonist, with evidence supporting its effectiveness in maintaining testosterone levels below the castration levels in PCa patients, as reported in the CS21 study [3]. Degarelix was approved by the Food and Drug Administration in 2008 and by the Pharmaceuticals and Medical Devices Agency of Japan in 2012. Degarelix blocks GnRH receptors in the pituitary gland, resulting in a rapid decrease in the production of testosterone, with suppression of testosterone to castrated levels that is normally achieved within 1-3 days $[4,5]$. Additional analysis of the CS21 study data revealed no significant difference between the effects of GnRH antagonist and GnRH agonist on prostate specific antigen (PSA) progression [6]. However, in patients with a PSA level $>20 \mathrm{ng} / \mathrm{ml}$, the use of $\mathrm{GnRH}$ antagonist significantly prolonged the time to recurrence of PSA elevation [6]. Degarelix also reduces the level of serum alkaline phosphatase (ALP) to a significantly greater extent in patients with bone metastases than does leuprorelin [7]. However, the effects of degarelix on androgen deprivation last for only 1 month; therefore, monthly administrations are required. The development of injection-site induration and pain are the main causes of treatment discontinuation with $\mathrm{GnRH}$ agonists. In contrast, GnRH antagonists are available in 1-, 3-, and 6-month depot formulations, and local reaction to subcutaneous injection of GnRH agonists is relatively rare, in comparison with degarelix. Therefore, it is common to switch from degarelix to a GnRH agonist once the testosterone levels are successfully reduced and stabilized. However, the possible effects of switching from degarelix to GnRH agonists on clinical and oncological outcomes in PCa have not been evaluated.

Hinotsu et al. reported a clinically acceptable progression-free survival and overall survival in patients treated with ADT for PCa [8]. However, in their study, a GnRH agonist was used for ADT and the time of transition from hormone sensitive prostate cancer (HSPC) to castration resistant prostate cancer (CRPC) was not investigated. To address these limitations, we retrospectively evaluated the overall survival and calculated the time of transition 
from HSPC to CRPC when treated with GnRH antagonist. We also evaluated the effects of switching from GnRH antagonist to $\mathrm{GnRH}$ agonist in PCa treatment on clinical and oncological outcomes.

\section{Methods}

We conducted a retrospective cohort analysis of patients with histologically confirmed adenocarcinoma of the prostate, who underwent ADT by GnRH antagonist therapy at Osaka City University Hospital and Bell Land General Hospital. This study included 108 patients who were treated with degarelix, at an initial dose of $240 \mathrm{mg}$ and maintenance dose of $80 \mathrm{mg}$. In 57 of these patients, degarelix was discontinued due to immediate achievement of decrease in PSA levels or due to adverse events of the drug, and a GnRH agonist (leuprorelin acetate or goserelin acetate) was used for maintenance therapy. Patients in whom degarelix was effective and who did not need switching to $\mathrm{GnRH}$ agonists continued degarelix. Adverse events due to degarelix were investigated monthly. In approximately all the patients $(94.4 \%)$, bicalutamide $(80 \mathrm{mg})$ was administered concomitantly with degarelix, and it was continued even after switching to GnRH agonists. Relevant characteristics of our patient groups are summarized in Table 1.

The overall survival, cancer-specific survival, time to CRPC, serum PSA, and levels of testosterone and ALP were investigated. PSA progression was defined according to the Prostate Cancer Clinical Trials Working Group criteria as a $25 \%$ increase from the baseline value, with an absolute increase of $2 \mathrm{ng} / \mathrm{mL}$ after 12 weeks of treatment [9]. The declines in PSA and ALP levels from baseline following treatment with degarelix were calculated, with the changes in ALP levels analyzed only in patients with bone metastases. PSA and ALP levels were also compared before and after switching the treatment from degarelix to GnRH agonist. Again, ALP was analyzed only in patients with bone metastases. Testosterone levels were not routinely measured except to determine if below castration levels were maintained after switching to the GnRH agonist.

Differences in clinicopathological variables were compared between the two groups (the 'continued' and the 'changed' groups) by chi-squared analysis. The Kaplan-Meier method was used to compare the overall and cancer specific survival rate, and time to CRPC, with between-group differences in survival curves evaluated using log rank tests. The changes in PSA and ALP levels between the two groups were evaluated using a paired t-test. All $p$-values were two-sided, and a $p$-value $<0.05$ was considered to be statistically significant. Statistical analysis was performed using Microsoft Excel ${ }^{\circ}$.
The access to the medical records of these patients was approved by the local research ethics committee at Osaka City University (approval number 4011).

\section{Results}

The reasons to switch from degarelix to $\mathrm{GnRH}$ agonist in the 57 patients in the 'changed group' were as follows: injection site induration and pain $(n=12)$; allergic reaction to degarelix $(n=1)$; and immediate decrease in PSA $(n=$ 44). Relevant characteristics were comparable between the two groups, except for the duration of follow-up (Table 1). Of note, compared with the patients on ADT for PCa in Japan [8], our study group included a higher proportion of cases with lymph node involvement and distal metastases. Additionally, the Gleason scores and initial PSA levels were relatively high in our study.

Of the 51 patients who continued degarelix (continued group), 3 patients died of $\mathrm{PCa}$ and 3 other patients died of a cerebrovascular accident, ischemic bowel disease, and unknown cause. Of the 57 patients in the changed group, only 1 patient died from acute myocardial infarction. Of the 108 patients who initially received degarelix, the 5-year overall survival rate, 5-year cancer-specific survival, and time to CRPC were 88.5, 95.0\%, and 41.1 months (95\% confidence interval (CI), 36.445.8 months), respectively. The overall survival was statistically superior in the 'changed' group in comparison with the 'continued' group, with a 5-year overall survival of 96.6 and $74.1 \%$, respectively ( $p=0.006)$ (Fig. 1a). The 5 -year cancer-specific survival was also superior in the changed (100\%) group compared with the continued (84.6\%) group ( $p=0.027$ ) (Fig. 1b). The time to CRPC is shown in Fig. 2 for both groups, with no between-group differences identified: 35.2 months in the continued group and 43.3 months in the changed group ( $p=$ 0.117). The median percentage decrease in PSA level for all patients treated with degarelix was $99.7 \%$ (range, 0 $100 \%$ ), with maintenance of the lowered levels even after switching to $\mathrm{GnRH}$ agonists in the 'changed' group (Table 2). The levels of ALP in patients with bone metastases were also suppressed by degarelix (median decrease, $46.4 \%$; range, $94.4 \%$ to $-144.4 \%$ ), with the level of ALP remaining constant after switching to GnRH agonists in the 'changed' group (Table 2). Furthermore, the switch to GnRH agonists did not affect the serum testosterone levels; they were maintained below the castration levels in the changed group $(0.09 \pm 0.05 \mathrm{ng} / \mathrm{ml})$.

\section{Discussion}

Ours is the first study to report that changing the treatment from a $\mathrm{GnRH}$ antagonist (degarelix) to a $\mathrm{GnRH}$ agonist did not affect the oncological outcomes in patients with hormone sensitive PCa. It is widely known that ADT is effective for the treatment of locally advanced PCa or 
Table 1 Patients' characteristics

\begin{tabular}{|c|c|c|c|c|c|c|}
\hline & & \multicolumn{2}{|c|}{ Degarelix (Continued group) } & \multicolumn{2}{|c|}{$\begin{array}{l}\text { Conversion from degarelix to GnRH } \\
\text { agonist (Changed group) }\end{array}$} & \multirow[t]{2}{*}{$p$ value } \\
\hline Number of patients & & & 51 & & 57 & \\
\hline Follow up duration (months) & median (range) & 19.4 & $(1.0-57.9)$ & 38.8 & $(2.2-58.6)$ & $<0.001$ \\
\hline Degarelix treatment duration (months) & median (range) & 14 & $(1-52)$ & 8 & $(1-39)$ & 0.064 \\
\hline Age (years) & median (range) & 73 & $(49-95)$ & 75 & $(50-90)$ & 0.572 \\
\hline \multirow[t]{4}{*}{ T stage } & $\mathrm{T} 1$ & 3 & $5.9 \%$ & 1 & $1.8 \%$ & \multirow[t]{4}{*}{0.387} \\
\hline & $\mathrm{T} 2$ & 10 & $19.6 \%$ & 18 & $31.6 \%$ & \\
\hline & T3 & 24 & $47.1 \%$ & 26 & $45.6 \%$ & \\
\hline & T4 & 14 & $27.4 \%$ & 12 & $21.1 \%$ & \\
\hline \multirow[t]{2}{*}{ N } & No & 29 & $56.9 \%$ & 31 & $54.4 \%$ & \multirow[t]{2}{*}{0.796} \\
\hline & $\mathrm{N} 1$ & 22 & $43.1 \%$ & 26 & $45.6 \%$ & \\
\hline \multirow[t]{2}{*}{ M } & MO & 16 & $31.4 \%$ & 23 & $40.4 \%$ & \multirow[t]{2}{*}{0.486} \\
\hline & M1 & 35 & $68.6 \%$ & 34 & $59.6 \%$ & \\
\hline \multirow[t]{6}{*}{ Gleason score } & 6 & 1 & $2.0 \%$ & 2 & $3.5 \%$ & \multirow[t]{6}{*}{0.389} \\
\hline & 7 & 5 & $9.8 \%$ & 6 & $10.5 \%$ & \\
\hline & 8 & 21 & $41.2 \%$ & 24 & $42.1 \%$ & \\
\hline & 9 & 15 & $29.4 \%$ & 15 & $26.3 \%$ & \\
\hline & 10 & 4 & $7.8 \%$ & 5 & $8.8 \%$ & \\
\hline & unknown & 5 & $9.8 \%$ & 5 & $8.8 \%$ & \\
\hline Initial PSA (ng/ml) & Median (range) & 145 & $(0.48-8072)$ & 122 & $(5.62-9675)$ & 0.669 \\
\hline \multirow[t]{4}{*}{ PSA } & PSA 0-4 & 1 & $2.0 \%$ & 0 & $0.0 \%$ & \multirow[t]{4}{*}{0.415} \\
\hline & PSA4-10 & 5 & $9.8 \%$ & 3 & $5.3 \%$ & \\
\hline & PSA10-20 & 2 & $3.9 \%$ & 5 & $8.8 \%$ & \\
\hline & $P S A>20$ & 43 & $84.3 \%$ & 49 & $86.0 \%$ & \\
\hline \multirow[t]{2}{*}{ Treatment } & $C A B$ & 48 & $94.1 \%$ & 54 & $94.7 \%$ & \multirow[t]{2}{*}{0.889} \\
\hline & GnRH only & 3 & $5.9 \%$ & 3 & $5.3 \%$ & \\
\hline \multirow[t]{2}{*}{ Transition to CRPC } & No & 37 & $72.5 \%$ & 38 & $66.7 \%$ & \multirow[t]{2}{*}{0.508} \\
\hline & Yes & 14 & $27.5 \%$ & 19 & $33.3 \%$ & \\
\hline$\%$ PSA decrease by degarelix & median (range) & $-99.4 \%$ & $(6.6-100.0)$ & $-99.8 \%$ & $(47.2-100.0)$ & 0.068 \\
\hline
\end{tabular}

Abbreviations $C A B$ combined androgen blockade, CRPC castration resistant prostate cancer, GnRH gonadotropin releasing hormone

metastatic PCa. As such, castration and GnRH agonist therapy remain the mainstream treatments for patients with advanced PCa. Results of the CS21 study [3] demonstrated that $\mathrm{GnRH}$ antagonists are effective in promptly reducing testosterone levels and suppressing the initial testosterone surge that is common in ADT. Therefore, results from the initial CS21 study with a 12-month follow-up, and its extended study to a 27.5-month follow-up [10], indicate that immediate disease control can be achieved with degarelix, a GnRH antagonist, which is comparable to that achieved with the use of GnRH agonists. However, long-term follow-up data on the clinical outcomes of degarelix use is not currently available. Furthermore, once stable disease status has been achieved, due to the negative effects of repeated monthly administration at the injection site, switching to $\mathrm{GnRH}$ agonists is common in patients with severe reactions to degarelix. The effects of this change in treatment on clinical outcomes have not been previously reported. These gaps in the current knowledge regarding the use of degarelix motivated us to conduct this study.

We report the first long-term survival data of degarelix. The 5-year overall and cancer-specific survival rates were high in both groups; $88.5 \%$ in the continued group and $95.0 \%$ in the changed group. Furthermore, considering the high Gleason score, serum PSA level, and high proportion of patients with metastatic PCa in our study group, degarelix in the treatment of $\mathrm{PCa}$ might be much more effective than expected. As a comparison, of the patients treated with ADT, Hinotsu et al. reported the following 5-year overall survival rates: $90 \%$ (stage II), $80 \%$ (stage III), and 60\% (stage IV) [8]. 


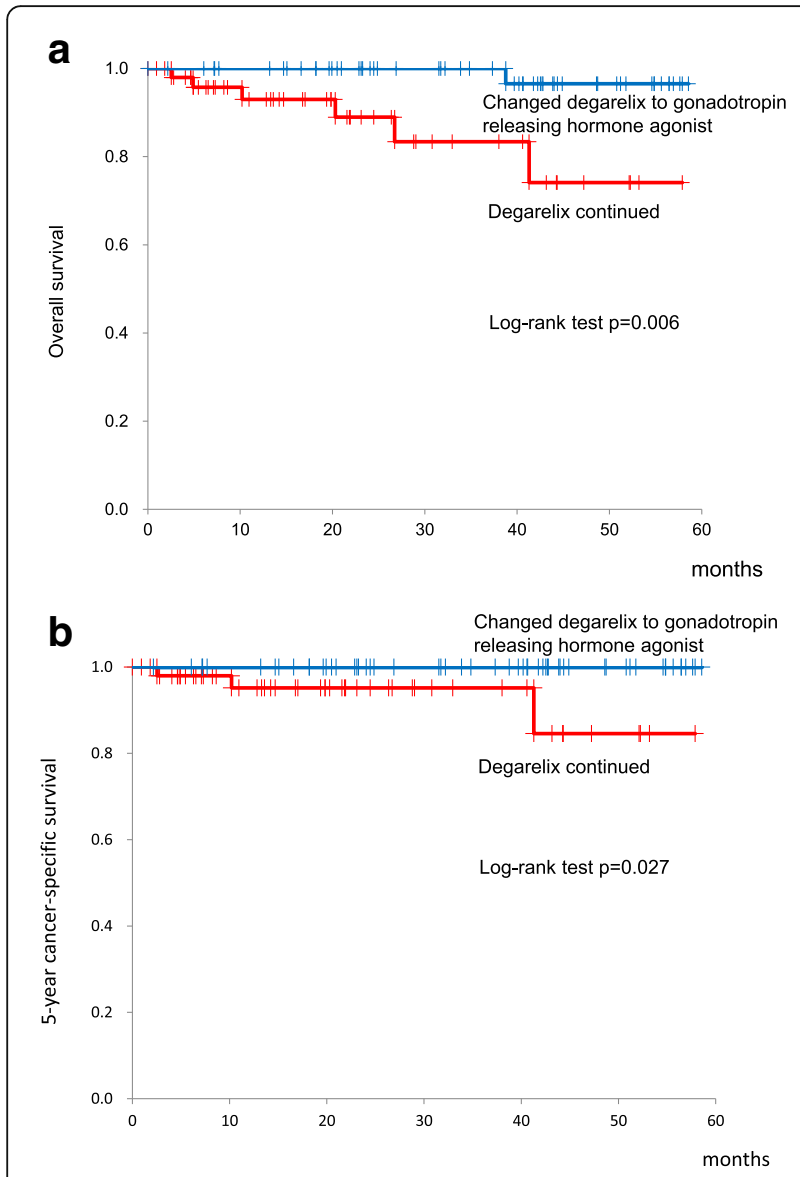

Fig. 1 Overall survival (a) and cancer specific survival (b) in patients treated with degarelix and patients in whom degarelix was switched to gonadotropin releasing hormone agonist

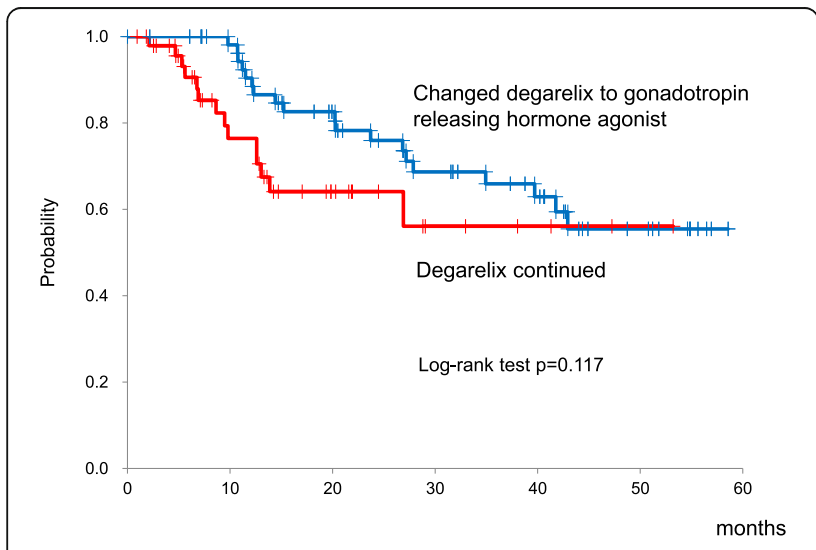

Fig. 2 Time to castration resistant prostate cancer in patients treated with degarelix and patients in whom degarelix was switched to gonadotropin releasing hormone agonist
It was obvious from this study that CRPC conversion took approximately 3-4 years, although it did not reach the median at the time of our data analysis. Few studies have reported on the time to CRPC in ADT. The ChemoHormonal Therapy Versus Androgen Ablation Randomized Trial for Extensive Disease in Prostate Cancer (CHAARTED) study by Sweeney et al. reported a median time to CRPC of 11.7 months in patients treated only with ADT [11]. Although baseline characteristics between our study cohort and the CHAARTED cohort were not equivalent, the differences in the time to CRPC might reflect the differences in the treatment of PCa between the two studies. In our study cohort, a majority of patients received antiandrogen drugs (bicalutamide $80 \mathrm{mg}$ ) in combination with degarelix. Akaza et al. reported a significant overall survival advantage favoring the use of combined androgen blockade (CAB) over GnRH agonist monotherapy (Cox regression analysis HR, 0.78) [12]. Similarly, Klotz et al. evaluated the efficacy of combining $\mathrm{CAB}$ therapy with bicalutamide $50 \mathrm{mg}$ using validated statistical methodology to combine the Prostate Cancer Trialists' Collaborative Group meta-analysis data [13] with data from a phase 3 trial of two $\mathrm{CAB}$ regimens (GnRH agonist plus bicalutamide $50 \mathrm{mg}$ versus $\mathrm{GnRH}$ agonist plus flutamide) [14]. Their analysis demonstrated that the combination of $\mathrm{CAB}$ with bicalutamide $50 \mathrm{mg}$ could reduce the risk of death by $20 \%$ compared with castration alone (HR, 0.80). In the CHAARTED study, the median overall survival was 13.6 months longer with ADT plus docetaxel than with ADT alone (57.6 months versus 44.0 months; HR for death in the combination group, 0.61 ; 95\% CI, $0.47-$ $0.80 ; P<0.001)$. Recently, the addition of abiraterone acetate and prednisone to ADT has significantly increased the overall survival and radiographic progression-free survival in metastatic HSPC [15]. Considering these data, it is likely that the overall survival can be extended with the use of ADT plus other drugs compared with GnRH antagonist/agonist monotherapy.

As previously described, continuous administration of degarelix is troublesome due to the adverse events (skin reaction at the injection site) and the frequency of hospital visits as degarelix is only available in 1-month doses. Therefore, it is common practice to change the treatment from degarelix to a GnRH agonist once a stable PCa status has been achieved. In their evaluation of the endocrine assessment of the gonadal axis in patients whose treatment was changed from a GnRH antagonist to GnRH agonist, Miyazawa et al. identified a testosterone surge in $8.3 \%$ of their study patients, with this surge being mild and of very short duration [16]. Furthermore, Miyazawa et al. did not observe a significant change in PSA levels after changing to the GnRH agonist leuprolide, and no patients reported symptoms 
Table 2 PSA and ALP change

\begin{tabular}{llll}
\hline & PSA before switch from GnRH antagonist to agonist & PSA after switch from GnRH antagonist to agonist & $p$ value \\
PSA (ng/ml) & $2.7 \pm 8.8$ & $2.0 \pm 5.1$ & 0.286 \\
& ALP before switch from GnRH antagonist to agonist & ALP after switch from GnRH antagonist to agonist \\
ALP (IU/L) & $378 \pm 545$ & $387 \pm 772$ & 0.905 \\
\hline
\end{tabular}

Abbreviations PSA prostate specific antigene, ALP alkaline phosphatase, GnRH gonadotropin releasing hormone

associated with a testosterone surge over the observation period. Based on their findings, they concluded that switching from degarelix to leuprolide (a GnRH agonist) appears to be a reasonable therapeutic option for patients with PCa. In our study cohort, the time to CRPC was comparable between patients in whom degarelix was continued and those in whom treatment was changed to a GnRH agonist, although the overall- and cancer-specific survival rates were statistically superior in those in whom treatment was changed. In agreement with Miyazawa et al., the change in ADT did not affect PSA and testosterone levels. Therefore, it is safe to conclude that switching from degarelix to a $\mathrm{GnRH}$ agonist is an effective treatment for PCa.

Assessment of ALP levels before and during PCa treatment might provide useful prognostic information, with ALP levels after 6 months of ADT being predictive of overall survival in patients with PCa $[17,18]$. Fritz et al. reported that degarelix successfully reduced ALP levels and maintained ALP suppression, although leuprolide did not [7]. Our study did not support this finding, with levels of ALP reduction achieved with degarelix being maintained after the change to a GnRH agonist in patients with $\mathrm{PCa}$ and bone metastasis. This result also confirms that switching from degarelix to a GnRH agonist does not affect the disease control.

This study is a retrospective study and, thus, has certain limitations, including a selection bias which might have influenced our results. Our observation period was different for patients who continued degarelix and those who switched. The relatively short period of observation, with few cases of death, particularly in the changed group, may have influenced our group comparisons of overall- and cancer-specific survival. Both localized PCa and metastatic cases were included in our study group. Localized PCa should first be treated using a local approach, prostatectomy, or radiation therapy. Hormone therapy may be used in selected cases, based on the treatment complications, age, and comorbidities, among other factors. Further studies are needed to clarify the outcomes of ADT in patients who actually require hormonal therapy.

\section{Conclusions}

Degarelix is effective in the treatment of prostate cancer. Degarelix therapy can also be safely changed to a GnRH agonist without any adverse clinical or oncological effects.

\section{Acknowledgements}

We would like to thank Editage (www.editage.jp) for English language editing.

\section{Availability of data and materials}

The datasets used and/or analysed during the current study are available from the corresponding author on reasonable request.

\section{Authors' contributions}

Conception and design, drafting of the manuscript: ST, JA, TO. Acquisition of data: TI, MK, TY, NN. Analysis and interpretation of data: ST, SY. Final approve of the manuscript: TN. All authors read and approved the final manuscript.

Ethics approval and consent to participate

Permission to access the database for a review of the medical records of these patients was obtained from the Local Research Ethics Committee at Osaka City University (approval number 4011).

\section{Competing interests}

The authors declare that they have no competing interests.

\section{Publisher's Note}

Springer Nature remains neutral with regard to jurisdictional claims in published maps and institutional affiliations.

\section{Author details}

${ }^{1}$ Department of Urology, Osaka City University Graduate School of Medicine, 1-4-3 Asahi-machi, Abeno-ku, Osaka 545-8585, Japan. Department of Urology, Bell Land General Hospital, 500-3, Higashiyama, Naka-ku, Osaka 599-8247, Japan.

Received: 25 February 2018 Accepted: 24 May 2018

Published online: 18 July 2018

\section{References}

1. Huggins C, Hodges CV. Studies on prostatic Cancer. I. The effect of castration, of estrogen and of androgen injection on serum phosphatases in metastatic carcinoma of the prostate. Cancer Res. 1941;1:293-7.

2. van Poppel H, Nilsson S. Testosterone surge: rationale for gonadotropinreleasing hormone blockers? Urol. 2008;71:1001-6.

3. Klotz L, Boccon-Gibod L, Shore ND, Andreou C, Persson BE, Cantor P, et al. The efficacy and safety of degarelix: a 12-month, comparative, randomized, open-label, parallel-group phase III study in patients with prostate cancer. BJU Int. 2008;102:1531-8.

4. Van Poppel H, Tombal B, de la Rosette JJ, Persson BE, Jensen JK, Kold Olesen T. Degarelix: a novel gonadotropin-releasing hormone $(\mathrm{GnRH})$ receptor blocker-results from a 1-yr, multicentre, randomised, phase 2 dosage-finding study in the treatment of prostate cancer. Eur Urol. 2008:54:805-13.

5. Gittelman M, Pommerville PJ, Persson BE, Jensen JK, Olesen TK. A 1-year, open label, randomized phase II dose finding study of degarelix for the treatment of prostate cancer in North America. J Urol. 2008;180:1986-92.

6. Tombal B, Miller K, Boccon-Gibod L, Schroder F, Shore N, Crawford ED, et al. Additional analysis of the secondary end point of biochemical recurrence rate in a phase 3 trial (CS21) comparing degarelix $80 \mathrm{mg}$ versus leuprolide in prostate cancer patients segmented by baseline characteristics. Eur Urol. 2010;57:836-42.

7. Schroder FH, Tombal B, Miller K, Boccon-Gibod L, Shore ND, Crawford ED, et al. Changes in alkaline phosphatase levels in patients with prostate cancer receiving degarelix or leuprolide: results from a 12-month, comparative, phase III study. BJU Int. 2010;106:182-7. 
8. Hinotsu S, Akaza H, Usami M, Ogawa O, Kagawa S, Kitamura T, et al. Current status of endocrine therapy for prostate cancer in Japan analysis of primary androgen deprivation therapy on the basis of data collected by J-CaP. Jpn J Clin Oncol. 2007:37:775-81.

9. Scher HI, Halabi S, Tannock I, Morris M, Sternberg CN, Carducci MA, et al. Design and end points of clinical trials for patients with progressive prostate cancer and castrate levels of testosterone: recommendations of the prostate Cancer clinical trials working group. J Clin Oncol. 2008;26:1 148-59.

10. Crawford ED, Tombal B, Miller K, Boccon-Gibod L, Schroder F, Shore N, et al. A phase III extension trial with a 1-arm crossover from leuprolide to degarelix: comparison of gonadotropin-releasing hormone agonist and antagonist effect on prostate cancer. J Urol. 2011;186:889-97.

11. Sweeney CJ, Chen YH, Carducci M, Liu G, Jarrard DF, Eisenberger M, et al. Chemohormonal therapy in metastatic hormone-sensitive prostate Cancer. N Engl J Med. 2015:373:737-46.

12. Akaza H, Hinotsu S, Usami M, Arai Y, Kanetake H, Naito S, et al. Combined androgen blockade with bicalutamide for advanced prostate cancer: longterm follow-up of a phase 3, double-blind, randomized study for survival. Cancer. 2009;115:3437-45.

13. Maximum androgen blockade in advanced prostate cancer: an overview of the randomised trials. Prostate cancer trialists' collaborative group. Lancet. 2000:355:1491-8.

14. Klotz L, Schellhammer P, Carroll K. A re-assessment of the role of combined androgen blockade for advanced prostate cancer. BJU Int. 2004;93:1177-82.

15. Fizazi K, Tran N, Fein L, Matsubara N, Rodriguez-Antolin A, Alekseev BY, et al. Abiraterone plus prednisone in metastatic, castration-sensitive prostate Cancer. N Engl J Med. 2017;377:352-60.

16. Miyazawa Y, Kato H, Arai S, Furuya Y, Sekine Y, Nomura M, et al. Clinical endocrinological evaluation of the gonadal axis (testosterone, LH and FSH) in prostate cancer patients switched from a $\mathrm{GnRH}$ antagonist to a LHRH agonist. Basic Clin Androl. 2015;25:7.

17. Johansen JS, Brasso K, Iversen P, Teisner B, Garnero P, Price PA, et al. Changes of biochemical markers of bone turnover and YKL-40 following hormonal treatment for metastatic prostate cancer are related to survival. Clin Cancer Res. 2007;13:3244-9.

18. Robinson D, Sandblom G, Johansson R, Garmo H, Stattin P, Mommsen S, et al. Prediction of survival of metastatic prostate cancer based on early serial measurements of prostate specific antigen and alkaline phosphatase. J Urol. 2008:179:117-22. discussion 122-113

\section{Ready to submit your research? Choose BMC and benefit from}

- fast, convenient online submission

- thorough peer review by experienced researchers in your field

- rapid publication on acceptance

- support for research data, including large and complex data types

- gold Open Access which fosters wider collaboration and increased citations - maximum visibility for your research: over $100 \mathrm{M}$ website views per year

At BMC, research is always in progress.

Learn more biomedcentral.com/submissions 